\title{
SOCIAL MEDIA AND PROTESTS ENGAGEMENT: WHAT'S GENDER GOT TO DO WITH IT?
}

\author{
Gustavo Hermínio Salati Marcondes de Moraes, \\ School of Applied Sciences, University of Campinas (UNICAMP) \\ Limeira - Sao Paulo, Brazil \\ Gisela Consolmagno Pelegrini \\ School of Applied Sciences, University of Campinas (UNICAMP) \\ Limeira - Sao Paulo, Brazil \\ Gabriela Trindade Pinheiro \\ School of Applied Sciences, University of Campinas (UNICAMP) \\ Limeira - Sao Paulo, Brazil
}

\begin{abstract}
Social media allows people to organize themselves and take action against social injustices and policies. Used to spread information, social media has been linked to the dissemination of political protests around the world. Relying on the Theory of Planned Behavior and Herd Behavior, this studied aimed at identifying gender differences in social network protests' participation. Making use of multivariate data analysis through Partial Least Squares Path Modeling (PLS-SEM), 318 Brazilians responded the study and the results indicate that there are differences between the relationships of the antecedents of the use of the social network between users of different genders. The differences are in the relationship between the attitude and the use of social networks to participate in protests, with a positive effect on men and negative on women. This means that men understand that participating in online protests through social networks can improve awareness of events, giving strength to the movement and helping to ease the tension of protests, while women do not. The results go beyond the studies on which they were based, including the gender multigroup analysis and presenting a new model of technological adoption with new elements, such as the herd behavior, embracing the imitation, and the uncertainty constructs. There is also a contribution to a greater understanding of the influence of social media on collective activism or movements.
\end{abstract}

Keywords: Social Media, Online Movements, Protests, Gender.

\section{INTRODUCTION}

Media is a powerful tool for communication and socialization (Fong et al., 2019). It has an important effect on perceived public opinion about the reality and it also allows dominant groups into shaping individuals' values, attitudes and opinions (Fong et al., 2019; Gitlin, 1980).Social media, for that matter,not only presents itself as a real-time intelligence tool to get business insights (Mirchandani \& Gaur, 2019) but also as an enabler for individuals to gather themselves and take action against social injustices and policies rapidly (Lance Bennett \& Segerberg, 2011). It enables individuals to mobilize others into taking part, either in a short or longlength, turning it into a challenge the persistence of these movements (Selander \& Jarvenpaa, 2016).
Facebook and Twitter are often considered as both disruptive and nondisruptive platforms that could shape political participation (Jost et al., 2018). Social media analysis enables opportunities to observe collective action and social movements behaviors (Jost et al., 2018). According toJostet al.(2018), social media use has been linked to the spread of political protests in several countries around the world (Hong Kong, Moscow, Kiev, Madrid, New York, Los Angeles, among others). This paper aims at identifying gender differences in social media protests' participation. The results may provide relevant information regarding online movements against social injustices, showing beliefs and the differences regarding the participants' motivations towards these movements. 
The comprehension of online communities and behavior is relevant once it may affect real-world outcomes and it also reflects on how citizens look for information and how they relate to media (Batista et al., 2017). In Latin America, online gender is a trend, especially when hashtags are analyzed (Batista et al., 2017). According to Batista et al., (2017), most trendy hashtags in 2015 among Brazilian userswere marked by gender issues (e.g. \#Feminism \#ViolenceCannotBeJustified, \#Feminist, \#SpeakWithoutFear) and also a political hashtag, such as the one in favor of firing the ex-president of Federal Chamber, in Federal Supreme Court (Batista et al., 2017).

Around the globe, studies on females' representativeness online behavior has been pointed as sparse (Fong et al., 2019), as women's participation in protests (regarding females' rights and also other subjects) are also under-researched (Roth \& Saunders, 2019), this paper intends to fill in the research gap, presenting an analysis of differences regarding the subject in Brazil.This article is structured in five chapters. The next section presents the theoretical background divided in three subjects, followed by the methodology,hypotheses, and results of the research. Afterward, adiscussionwith conclusions, limitations, and opportunities for future studies are going to be exposed.

\section{LITERATURE REVIEW}

This chapter presents a literature review on the main topics of this research, as it is structures: (2.1) Activism and Movements through Social Media, introducing studies about movements through social network and the current significance, (2.2) Behavior Theories Related to Information Technology, in which is presented theoretical behavior model supporting the technological information and (2.3) Females' use of Social Media presenting gender participation in this manner of activism.

\section{Activism and movements through social media}

Social media engage an important role in information diffusion, mainly referring to online social movements, connecting people promptly (Isa \& Himelboim, 2018), and has proved to be very potent in many situations (Howard et al., 2011; Hughes \& Palen, 2009), attracting the attention of researches(Boyd \& Ellison, 2007).

The online social movements are heterogeneous due to the different modes of strategies and actions developed by the social actors and their particular reasons for participation (Passy \& Giugni, 2001), and can be understood as the popular access to claiming their rights or even as the participation in the democratic process of public policies according to a specific context.

As an effective tool for activists and social movements, it provides human interaction resulting in successful outcomes, such as the movement to free Al Jazeera journalists imprisoned by Egyptian authorities between 2013 and 2015 (Isa \& Himelboim, 2018), the impact on the Arab Spring between 2014 and 2016 (Howard et al., 2011),mass convergence to manage emergencies in the politic field (Hughes \& Palen, 2009)or social movements, as My Stealthy Freedom against the compulsory veiling of women in Iran (Stewart \& Schultze, 2019), among others.

However, the use of social networks does not assure the success of the movements. The results of a study carried out to identify factors that led people to use social media to participate in the protests that occurred in 2013 in Brazil demonstrated disbelief about any positive effect on solving problems. Nevertheless, the intended to continue protesting virtually remained(Moraes et al., 2018).

\section{Behavior theories related to information technology}

To identify factors that led people to use social networks to participate in the social movements, a model has been developed based on some theories and constructs used in the Information Technology (IT) area, in the technological adoption field.

The Theory of Reasoned Action (TRA) proposes that an individual behavior is determined by the person's intention to perform a behavior and, consequently, this intention is determined by the attitude towards the behavior and the subjective norms (Fishbein \& Ajzen, 1975). Therefore, it is necessary to understand the individual beliefs as well as the environmental context, 
determinants of the normative, and attitude components (Fishbein \& Ajzen, 1975).

The Theory of Planned Behavior (TPB) was developed as an extension of TRA, adding the perceived behavioral control construct, which influences both intention and behavior(Ajzen, 1991). The relative importance of attitude, subjective norm, and perceived behavioral control in predicting intention fluctuate according to the different situations to which the theory is applied.

According to TPB, human behavior is based on behavioral beliefs, that is the possible consequences of human behavior leading to a favorable or unfavorable behavioral attitude, on normative beliefs, which would be the social pressure on behavior, and also on beliefs about control, referring to factors that can facilitate or impede the performance of the individual's behavior (Ajzen, 1991).

The behavioral attitude concerns, in this work, to the respondent's understanding about the possibility of their participation in an online social movement contributing to better awareness about the subject, strengthening the movement, contributing to the current debate, and increasing the importance of social actions. Beliefs about control, in this present study, refer to the perception of ease or difficulty in using social networks to participate in protests and activism, as post, share and comment posts about movements.

In contrast, the subjective norm construct was not considered the most appropriate for this research(Krueger et al., 2000), and constructs referring to research on Herd Behavior (HB) toward the use of IT(Walden \& Browne, 2009) were used to replace these values. Researches about HB have been carried out in different situations, such as the downloading software applications (Duan et al., 2009; Moraes, 2016; Walden \& Browne, 2009), and the development of television programs (Kennedy, 2003), and, in general, two primary conditions are necessary for the occurrence of HB: uncertainty about the own decision and observation of the others' actions.

\section{Females' use of Social Media}

The use of internet and social networks for political or social engagement has attracted researchers' attention in the past decades
(Schuster, 2013). Discussions approach how online activism could actually reach the real world (Livingstone et al., 2005), other even points that Facebook accounts have been disregarded when it comes to political participation (Christensen, 2011; Schuster, 2013). While several researches suggest many ways on how social media can impact on collective action (Selander \& Jarvenpaa, 2016; Valenzuela, 2013; Valenzuela et al., 2016), few has dedicated efforts to understand females' behavior regarding protests participation (Loiseau \& Nowacka, 2015; Schuster, 2017).

Social media has proved itself as a powerful tool to bring females' interests and rights to public knowledge (Loiseau \& Nowacka, 2015). The unprecedented use of social media by women represents an important step to bring opportunities and several discussions regarding (in)equality, gender gap, among others into media attention (Loiseau \& Nowacka, 2015).

Easy access and low in cost, online participation in protests is a preference for many young women, especially the ones who lack of resources, furthermore, this option enables a choice regarding how much of their identity will be exposed (Schuster, 2013).

In Brazil, political movements in 2013 were marked by a strong online engagement and participation, which brought a different way of making protests in the country (Queiroz, 2017), during 2018s presidential election, females created the world famous hashtag \#EleNão (\#NotHim)(Baronas et al., 2019).

Regarding females' participation on online activism, the literature points to a wave of feminist forces trying to direct efforts into transforming online social movements into actual change: the Feminist fourth wave (Hollanda, 2018). According to the author(Hollanda, 2018), this new wave would be marked by the intense use of social media as important vectors of change.

Accordingly, it is within the online environment where women organize themselves and take a stand against abuse, gender discrimination, by developing a support network, where it is possible toshare stories and testimonials, and also organizing campaigns, social actions and protests 
(Madsen, 2015). Differently from previous decades, the internet and social media enable a much broader capability of information dissemination, where people could get information and also debate their ideas (Madsen, 2015).

On the other hand, previous research on females' behavior towards political engagementpoints to evidence that women engagein less visible political behaviors on social media because they are more likely to use social media for relationship maintenance and seem to be able to overcome political's confrontations and exposure(Bode, 2017).

\section{METHODOLOGY}

The research was developed through a quantitative methodology, with the use of multivariate data analysis. Due to social movements online theories are less developed and the objectives are the constructs hereby presented, Partial Least Squares Path Modeling (PLS-SEM) was chosen to reach this paper's objectives (Hair et al., 2017).

The preliminary questionnaire was evaluated by a group composed by 5 specialists in Information Technology area, who had already used models of technology adoption to asses content validity of the statements (Netemeyer et al., 2003). Five potential respondents were used to perform a pre-test with the questionnaire. Scales were adapted from previous studies. The questionnaire was posted in social media through a link in groups of social movements. The sample accounted with 318 respondents, once others were discarded due to incomplete answers. As recommended by the literature (Chin \& Newsted, 1999), to evaluate sample's size and statistic power, $G^{*}$ Power 3.1.5 was used (Cohen, 1988). Considering the predictors, significance level of $5 \%$, statistical power of 0.8 and average effect size ( $\mathrm{f}^{2}=0.15$, which is equivalent to $\mathrm{r}^{2}=13 \%$ ), we have that the minimum sample size is of 77 . As the sample was 318 respondents, it is suitable for estimation by PLS-PM.

The sample included $55 \%$ of male respondents, and $45 \%$ of female respondents. Most respondents were young, aged between 16 and 19 years old (50\%). 30\% were 20 and 29 years old and the remaining $20 \%$ were over 30 years old.

The post hoc analyzes for the sample obtained indicate that: (a) any $\mathrm{r}^{2}$ greater than $3.35 \%$ would be detected as significant, maintaining the power of 0.8 and a significance level of $5 \%$; and (b) for the medium effect size, the power is 0.999 , which is well above the recommended value of 0.8 (Hair et al., 2017).The SmartPLS 3.0M3 software (Ringle et al., 2015) was used for calculations and validations of statistical tests.

\section{HYPOTHESES}

This paper had as an objective to identify gender differences in protest's participation through social media. Therefore, the main hypothesis for this research is described as follows:

Hypothesis 1: There are differences between the relationships of the antecedents of behavior of using social networks to protest among users of different genders.

In this context, the paper's sub-hypotheses were developed based on the main theories in the area of information technology that were related to the focus of the research.

The first two sub-hypotheses of the study were based on TPB:

Hypothesis 1a: There are gender differences in the relationship between attitude towards behavior and the use of social networks to participate in protests.

Hypothesis 1b: There are gender differences in the relationship between perceived behavioral control and the use of social networks to participate in protests.

The third and fourth sub-hypotheses of the study are related to herd behavior when using IT:

Hypothesis 1c: There are gender differences in the relationship between imitation and the use of social networks to participate in protests.

Hypothesis 1d: There are gender differences in the relationship between uncertainty and imitation.

Figure 1 presents the conceptual model of research: 


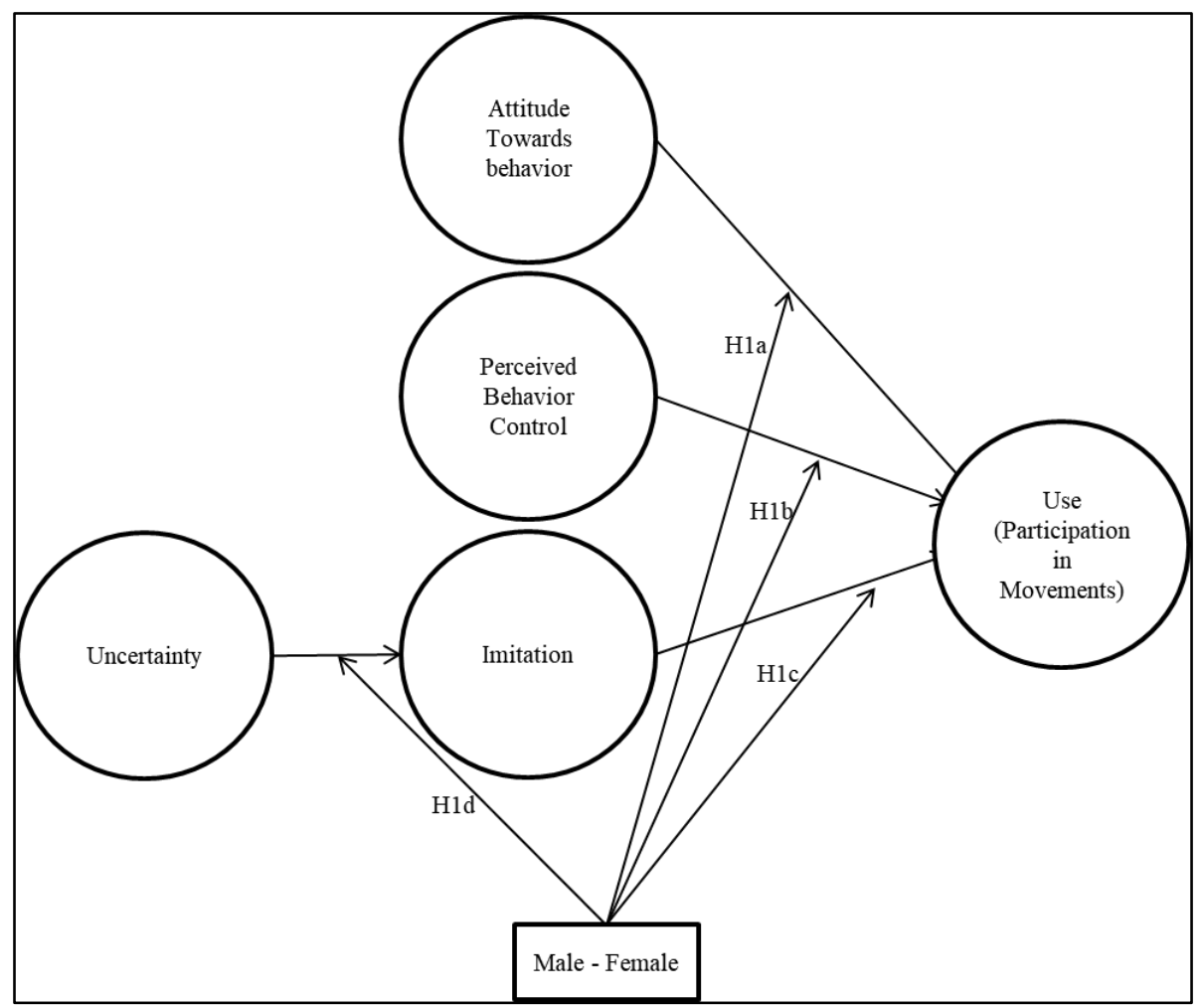

Figure 1: Research conceptual model.

It is acknowledging the existence of other influential factors on the use of social network and protests' participations online, however, the hypotheses presented in this paper show a broader relationship to the chosen object of study.

\section{RESULTS ANALYSIS}

The model's indicators are reflective, and the criteria for evaluation are: internal consistency, reliability of the indicator, convergent validity and discriminant validity (Hair et al., 2017).

The discriminant and convergent validities were assessed at the level of indicators and latent variables. In the analysis of crossed factor loads, all indicators showed high factor loads in their latent variables, greater than 0.70 , and low in the other latent variables.

Another indicator used for convergent validation of the model is the value of the average variance extracted (AVE), which, as a criterion for validation, must present a value greater than 0.5 (Hair et al., 2017).

To assess the measurement model, the composite reliability of each construct was also used (Hair et al., 2017). To analyze the convergent validity, the internal consistency was verified. Another indicator of discriminant validity between the constructs is to calculate the square root of the average variance extracted from the constructs. Table 1 presents these values, the square root of the average variance extracted is shown in bold diagonally, this value must be greater than the correlation between the latent variables (Fornell \& Larcker, 1981). Table 1 presents all the indicators mentioned and shows that all values are within the limits established by the authors.

Table 1 Summary of evaluation measurement models

\begin{tabular}{llllll}
\hline & Attitude & BC & IM & UNC & USE \\
\hline Attitude & $\mathbf{0 , 7 5 3}$ & & & & \\
BC & 0,421 & $\mathbf{0 , 8 3 9}$ & & & \\
IM & 0,361 & 0,321 & $\mathbf{0 , 9 0 8}$ & & \\
UNC & 0,191 & 0,093 & 0,613 & $\mathbf{0 , 8 5 8}$ & \\
USE & 0,493 & 0,549 & 0,587 & 0,342 & $\mathbf{0 , 8 3 8}$ \\
\hline & & & & & \\
\hline AVE & 0,567 & 0,703 & 0,824 & 0,737 & 0,701 \\
$\begin{array}{l}\text { Cronbach's } \\
\text { Alpha }\end{array}$ & 0,754 & 0,861 & 0,929 & 0,883 & 0,857 \\
$\begin{array}{l}\text { Composite } \\
\text { reliability }\end{array}$ & 0,840 & 0,904 & 0,949 & 0,918 & 0,904 \\
\hline
\end{tabular}

Note: $\mathrm{BC}=$ Behavioral Control; IM = Imitation; $\mathrm{UNC}=$ Uncertainty 
Before evaluating the structural model, it is necessary to assess the collinearity of the structural model. To assess collinearity, the VIF values were analyzed for each subpart of the structural model. All values are within the established, below 5 (Hair et al., 2017).

To analyze the meanings of the indicators, a bootstrapping technique was used(Efron \& Tibshirani, 1998). A Student's T test analyzes a hypothesis that the correlation coefficients are equal to zero. If the results of this test indicate values greater than 1.96, a rejected hypothesis and significant correlation (Efron \& Tibshirani, 1998; Hair et al., 2017).
Table 3: Results of $R 2$, adjusted $R 2$, and $Q 2$ values

\begin{tabular}{lcc}
\hline Construct & R2 & Q2 \\
\hline Imitation & 0.376 & 0.102 \\
Use & 0.541 & 0.207 \\
\hline
\end{tabular}

For SEM models, $\mathrm{Q}^{2}$ values greater than zero for a specific reflective endogenous latent variable indicate the predictive relevance of the path model. In the case of this study, the value is greater than zero.

To test the hypotheses of the study in relation to differences between relationships and

Table 2: Coefficients of the Structural Model

\begin{tabular}{lcccc}
\hline Relationships & Average & Standard error & T Value & P-value \\
\hline Attitude -> Use & 0,177 & 0,067 & 2,521 & 0,012 \\
BehavioralControl -> Use & 0,313 & 0,072 & 4,292 & 0,000 \\
Imitation -> Use & 0,351 & 0,073 & 4,912 & 0,000 \\
Uncertainty ->Imitation & 0,617 & 0,069 & 8,907 & 0,000 \\
\hline
\end{tabular}

Table 2 presents the coefficients of the structural model. The relationships are imposed by the values of the construction coefficients and as Student's T statistics. All the values of the arguments presented show $\mathrm{T}$ Values above 1.96 and P-values below 0.05 (significance level $=5 \%$ ).

Thus, these results guarantee the significance of relationships and allow differences between genders to be tested.

According to the analysis, the Use construct presented a $\mathrm{r}^{2}$ determination coefficient of 0.541, considered high, and the Imitation construct presented an $\mathrm{r}^{2}$ of 0.376 , considered high as well. In addition to evaluating the magnitude of $\mathrm{r}^{2}$ values as a predictive precision criterion, the $\mathrm{Q}^{2}$ value, which is an indicator of predictive relevance of the model, was evaluated. The $\mathrm{Q}^{2}$ measure applies an example reuse technique that omits part of the data matrix and uses model estimates to predict the omitted part. Specifically, when a PLS-SEM model has predictive relevance, it accurately predicts indicator data points in reflective measurement models. Table 3 shows the values of r2, adjusted r2 and Q2. gender differences, a multigroup analysis was performed.Table 4 presents the results of the analysis of the significant relationships of the constructs between groups of male and female respondents.

Table 4: Relationship differentiation analysis - Genders

\begin{tabular}{|c|c|c|c|}
\hline & & $\begin{array}{l}\text { Coefficientdifference } \\
\text { - Gender }\end{array}$ & $\begin{array}{l}\text { p- } \\
\text { Valu } \\
\text { e }\end{array}$ \\
\hline $\begin{array}{l}\text { Attitude } \\
\text { Use }\end{array}$ & $->$ & 0,341 & 0,016 \\
\hline BC -> Use & & 0,103 & 0,229 \\
\hline IM -> Use & & 0,206 & 0,914 \\
\hline UNC -> IM & & 0,122 & 0,167 \\
\hline
\end{tabular}

Note: $\mathrm{BC}=$ Behavior Control; IM = Imitation; $\mathrm{UNC}=$ Uncertainty

From the results of Table 4 , it is observed that there are significant differences only in the relationship between Attitude and Use in terms of gender. The effect is positive in males (0.330) and negative in females (-0.011).

\footnotetext{
Improved Model and Synthesis of Hypotheses Tests

The adjusted model resulting from the research is presented in Figure 2.
} 


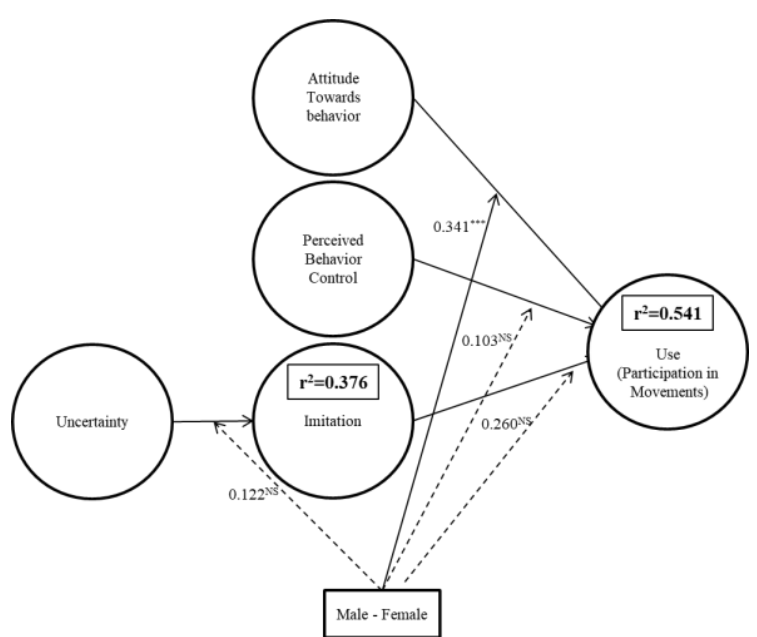

Figure 2: Complete empirical model

Note: * = significant at $5 \%$; ${ }^{*}=$ significant at $1 \% ; * *=$ significant at $0.1 \% ; \mathrm{NS}=$ not significant

With the obtained validations, the synthesis of the hypothesis tests of the study follows in Table 5 .

Table 5: Hypotheses confirmation

\begin{tabular}{|c|c|c|}
\hline Hypotheses & Description & Results \\
\hline H1 & $\begin{array}{l}\text { There are differences } \\
\text { between the } \\
\text { relationships of the } \\
\text { antecedents of behavior } \\
\text { of using social networks } \\
\text { to protest among users } \\
\text { of different genders. }\end{array}$ & Confirmed \\
\hline H1a & $\begin{array}{l}\text { There are gender } \\
\text { differences in the } \\
\text { relationship between } \\
\text { attitude towards } \\
\text { behavior and the use of } \\
\text { social networks to } \\
\text { participate in protests }\end{array}$ & Confirmed \\
\hline $\mathrm{H} 1 \mathrm{~b}$ & $\begin{array}{l}\text { There are gender } \\
\text { differences in the } \\
\text { relationship between } \\
\text { perceived behavioral } \\
\text { control and the use of } \\
\text { social networks to } \\
\text { participate in protests. }\end{array}$ & $\begin{array}{l}\text { Not } \\
\text { Confirmed }\end{array}$ \\
\hline $\mathrm{H} 1 \mathrm{c}$ & $\begin{array}{l}\text { There are gender } \\
\text { differences in the } \\
\text { relationship between } \\
\text { imitation and the use of } \\
\text { social networks to } \\
\text { participate in protests. }\end{array}$ & $\begin{array}{l}\text { Not } \\
\text { Confirmed }\end{array}$ \\
\hline H1d & $\begin{array}{l}\text { There are gender } \\
\text { differences in the } \\
\text { relationship between } \\
\text { uncertainty } \\
\text { imitation. }\end{array}$ & $\begin{array}{l}\text { Not } \\
\text { Confirmed }\end{array}$ \\
\hline
\end{tabular}

Regarding the attitude construct, the results show that the attitude effect on participation in protests by social networks influences positively in men and negatively in women. In other words, men believe that using the hashtag can contribute to improve awareness of events and strengthen protest movements, women do not believe.

The high explanatory value of the imitation construct demonstrates that people used social media to imitate other people, be they known, personality or artists. The values obtained in the construct uncertainty enhance this result and show the behavior of the herd in this case, demonstrating that people imitated others, even though they were not sure of the whole context about the movements. In the case of this relationship, there are no differences in behavior between men and women.

Another factor of high impact in the use of the application was Behavioral Control. This result indicates that the fact that using the application is easy for the respondent audience,makes it more used. In this relationship, there are also no differences between genders.

\section{DISCUSSION}

The selection of both constructs use of social networks for participation in movement and imitation are reasonably explained by the values of the coefficient of determination equal to $54.10 \%$ and $37.60 \%$, respectively. Farther, the study demonstrates that participation in online movements through social networks is explained by the constructs attitude, behavioral control, and imitation preceded by uncertainty.

The results of the presented model go beyond the studies on which they were based, including the gender multigroup analysis and presenting a new model of technological adoption with new elements, such as the herd behavior, embracing the imitation, and the uncertainty constructs. There is also a contribution to a greater understanding of the influence of social media on collective activism or movements(Gil de Zúñiga et al., 2012; Lance Bennett \& Segerberg, 2011).

In order to identify gender differences in social network protests' participation, the results feature relevant effect, between gender, of the 
attitude on participation in protests by social networks influences.The positive effect verified for the male gender could indicate that, in his understanding, participating in online protests through social media can improve awareness of the events, giving strength to the movement and helping to reduce the tension of the protests. For women, the effect is almost null, with negative values, which leads to the conclusion that females do not participate in movements thinking about participation as helping raise awareness or strengthen the movement.This attitude towards the female gender can be explained through studies on female political engagement, where there is evidence that women engaging in less visible political behaviors on social media because they are more likely to use social media for relationship maintenance and seem to be able to overcome political's confrontations and exposure(Bode, 2017).

Although the results show the influence of the attitude's effect in protests by social networks has been positive in relation to men and negative in relation to women, this subject is still in an incipient stage of study andthere is still unexamined proofs.Such evidence is presented as the phenomenon of the hashtag \#EleNão (\#NotHim), created mostly by Brazilian female citizens and shared worldwide, what evidence an opportunity of engrossing in this theme.

Meanwhile, the difference between genders for the other relationshipswas not confirmed through this analysis, being the tendency to imitate through social networks when there is no deep knowledge about the subject explained by $\mathrm{HB}$ is the same between males and females, as well as the perceived behavioral control at the use of social networks to participate in protests.

Among the limitations of the study, can be highlighted the representativeness of the sample,which included only Brazilians who participated in social networks, and the crosssection nature of data, that also hinders the analysis to understand how the association between variables of interest evolve over times.

As suggestions for future research, it is recommended to review the questionnaire and adapt it to a wider range of real situations that represent the constructs, test the model presented in new technologies, and with a larger sample, test other moderators and conduct longitudinal studies with qualitative methodologies.

\section{REFERENCES}

Ajzen, I. (1991). The theory of planned behavior. Organizational Behavior and Human Decision Processes, 50(2), 179-211. https://doi.org/10.1016/0749-5978(91)90020$\mathrm{T}$

Baronas, R. L., Lourenço Costa, J., \& Ponsoni, S. (2019). Artículo Os tecnografismos a partir da hashtag \#EleNão Tecnographisms from the hashtag \#NotHim (Vol. 13, Issue 3). www.dissoc.org

Batista, D. C., Silva, T., Stabile, M., Páez, P. C., \& Kearney, M. C. (2017). Insights from Social Media on Gender in Latin America. In InterAmerican Development Bank.

Bode, L. (2017). Closing the gap: gender parity in political engagement on social media. Information Communication and Society, 20(4), 587-603.

https://doi.org/10.1080/1369118X.2016.12023 02

Boyd, D. M., \& Ellison, N. B. (2007). Social Network Sites: Definition, History, and Scholarship. Journal of Computer-Mediated Communication, 13(1), 210-230. https://doi.org/10.1111/j.1083-

6101.2007.00393.x

Chin, W. W., \& Newsted, P. R. (1999). Structural equation modeling analysis with small samples using PLS. In R. H. Hoyle (Ed.), Statistical strategies for small sample research. SAGE PUBLICATIONS INC.

Christensen, H. S. (2011). Political activities on the Internet: Slacktivism or political participation by other means? First Monday. https://doi.org/https://doi.org/10.5210/fm. v16i2.3336

Cohen, J. (1988). Statistical Power Analysis for the Behavioral Sciences Second Edition(2nd Editio). Lawrence Erlbaum Associates.

Duan, W., Gu, B., \& Whinston, A. B. (2009). Informational cascades and software adoption on the Internet: An empirical investigation. MIS Quarterly: Management Information Systems. https://doi.org/10.2307/20650277 
Efron, B., \& Tibshirani, R. J. (1998). An introduction to the bootstrap. Champman \& Hall. CRC Press.

Fishbein, M., \& Ajzen, I. (1975). Belief, attitude, intention, and behavior: An introduction to theory and research. In Reading, MA. AddisonWesley.

Fong, Y. L., Esther, S., \& Nyathi, C. (2019). Gender Representation and Framing of Malaysian Women: A Study of Feature Articles in Female Magazine. Community $\mathcal{E}$ Communication Amity School of Communication, 10 , 2456-9011. https://doi.org/10.31620/JCCC.12.19/04

Fornell, C., \& Larcker, D. F. (1981). Evaluating Structural Equation Models with Unobservable Variables and Measurement Error. In Source: Journal of Marketing Research (Vol. 18, Issue 1).

Gil de Zúñiga, H., Jung, N., \& Valenzuela, S. (2012). Social Media Use for News and Individuals' Social Capital, Civic Engagement and Political Participation. Journal of ComputerMediated Communication, 17(3), 319-336. https://doi.org/10.1111/j.10836101.2012.01574.x

Gitlin, T. (1980). The whole world's watching (First Edit). University of California Press.

Hair, J. F., Hult, G. T. M., Ringle, C. M., \& Sarstedt, M. (2017). A primer on partial least squares structural equation modeling (PLSSEM). Thousand Oaks: SAGE Publications. https://doi.org/10.1080/1743727x.2015.10058 06

Hollanda, H. B. de. (2018). Explosão Feminista (1st Editio). Companhia das Letras.

Howard, P. N., Duffy, A., Freelon, D., Hussain, M. M., Mari, W., \& Mazaid, M. (2011). Opening Closed Regime: What Was the Role of Social Media During the Arab Spring? Project on Information Technology \& Political Islam, $1-30$. https://doi.org/http://dx.doi.org/10.2139/ss rn.2595096

Hughes, A. L., \& Palen, L. (2009). Twitter adoption and use in mass convergence and emergency events. ISCRAM 2009 - 6th International Conference on Information Systems for Crisis Response and Management: Boundary Spanning Initiatives and New Perspectives, 6, 248-260.
Isa, D., \& Himelboim, I. (2018). A Social Networks Approach to Online Social Movement: Social Mediators and Mediated Content in \#FreeAJStaff Twitter Network. Social Media and Society, 4(1), 1-14. https://doi.org/10.1177/2056305118760807

Jost, J. T., Barberá, P., Bonneau, R., Langer, M., Metzger, M., Nagler, J., Sterling, J., \& Tucker, J. A. (2018). How Social Media Facilitates Political Protest: Information, Motivation, and Social Networks. Political Psychology, 39(December), 85-118. https://doi.org/10.1111/pops.12478

Kennedy, R. E. (2003). Strategy Fads and Competitive Convergence: An Empirical Test for Herd Behavior in Prime-Time Television Programming. The Journal of Industrial Economics. https://doi.org/10.1111/14676451.00168

Krueger, N. F., Reilly, M. D., \& Carsrud, A. L. (2000). COMPETING MODELS OF ENTREPRENEURIAL INTENTIONS. 9026(98), 411-432.

Lance Bennett, W., \& Segerberg, A. (2011). DIGITAL MEDIA AND THE PERSONALIZATION OF COLLECTIVE ACTION: Social technology and the organization of protests against the global economic crisis. 14(6), 770-799.

https://doi.org/10.1080/1369118X.2011.57914 1

Livingstone, S., Bober, M., \& Helsper, E. J. (2005). Active participation or just more information? Young people's take-up of opportunities to act and interact on the Internet. Information Communication and Society, $8(3)$, 287-314. https://doi.org/10.1080/13691180500259103

Loiseau, E., \& Nowacka, K. (2015). Can social media effectively include women's voices in decision-making processes?

Madsen, N. (2015). MULHERES E COMUNICAÇÃO NO BRASIL: 1995 A 2015. IPEA.

Mirchandani, A., \& Gaur, B. (2019). Current trends \& future prospects of social media analytics in business intelligence practices. Journal of Content, Community and Communication, 9(2019), 123-130. https://doi.org/10.31620/JCCC.06.19/17

Moraes, G. H. S. M. (2016). Comportamento de 
Rebanho no Uso da Tecnologia de Informação. Revista IEEE América Latina, 14(8).

Moraes, G. H. S. M., Cappellozza, A., \& Soares Silva, D. (2018). Technology and the Dissemination of Information to participate in Protests through Social Networks. IEEE Latin America Transactions, 16(1), 287-293. https://doi.org/10.1109/TLA.2018.8291486

Netemeyer, R. G., Bearden, W. O., \& Sharma, S. (2003). Scaling Procedures. SAGE PUBLICATIONS INC. https://doi.org/https://dx.doi.org/10.4135/9 781412985772

Passy, F., \& Giugni, M. (2001). Social networks and individual perceptions: Explaining differential participation in social movements. Sociological Forum, 16(1), 123-153. https://doi.org/10.1023/A:1007613403970

Queiroz, E. de F. C. (2017). Ciberativismo: a nova ferramenta dos movimentos sociais. Panorama, 7(1), 2. https://doi.org/10.18224/pan.v7i1.5574

Ringle, C. M., Wende, S., \& Becker, J. M. (2015). SmartPLS 3. www.smartpls.com

Roth, S., \& Saunders, C. (2019). Social Movement Studies Do gender regimes matter? Gender differences in involvement in anti-austerity protests-a comparison of Spain, Sweden and the United Kingdom. https://doi.org/10.1080/14742837.2019.16762 22

Schuster, J. (2013). Invisible feminists? Social media and young women's political participation. Political Science, 65(1), 8-24. https://doi.org/10.1177/0032318713486474
Schuster, J. (2017). Political Science Invisible feminists? Social media and young women's political participation. https://doi.org/10.1177/0032318713486474

Selander, L., \& Jarvenpaa, S. (2016). Digital Action Repertoires and Transforming a Social Movement Organization.

Stewart, M., \& Schultze, U. (2019). Producing solidarity in social media activism: The case of My Stealthy Freedom. Information and Organization, 29(3), 100251. https://doi.org/10.1016/j.infoandorg.2019.04. 003

Valenzuela, S. (2013). Unpacking the Use of Social Media for Protest Behavior: The Roles of Information, Opinion Expression, and Activism. American Behavioral Scientist, 57(7), 920-942.

https://doi.org/10.1177/0002764213479375

Valenzuela, S., Somma, N. M., Scherman, A., \& Arriagada, A. (2016). Social media in Latin America: deepening or bridging gaps in protest participation? Online Information Review, 40(5), 1468-4527. https://doi.org/10.1108/OIR-11-2015-0347

Walden, E. A., \& Browne, G. J. (2009). Sequential adoption theory: A theory for understanding herding behavior in early adoption of novel technologies. In Journal of the Association for Information Systems (Vol. 10, Issue 1, pp. 31-62). Association for Information Systems. https://doi.org/10.17705/1jais.00181 